\title{
Farinha de linhaça dourada como substituto de gordura animal em hambúrguer de carne bovina com redução de sódio
}

\section{Golden flaxseed flour as a substitute for animal fat in reduced-sodium beef hamburgers}

\section{Autores | Authors}

\ Débora Francielly de Oliveira

Universidade Federal de Rondônia (UNIR) Departamento de Engenharia de Alimentos Av. Tancredo Neves, 3450, Setor Institucional

CEP: 76872-862 Ariquemes/RO - Brasil e-mail: debora.oliveira@unir.br

João Paulo Fernando MILESKI Caroline Giane de CARLI João Francisco MARCHI

Universidade Tecnológica Federal do Paraná (UTFPR)

Departamento Tecnologia de Alimentos

Francisco Beltrão/PR - Brasil e-mail: joaomileski@utfpr.edu.br caroline_gianedecarl@hotmail.com joaomarchi@utfpr.edu.br

Davi Costa SILVA

Universidade Tecnológica Federal do Paraná (UTFPR)

Departamento Tecnologia de Alimentos Pato Branco/PR - Brasil e-mail:davisilva@utfpr.edu.br

Alexandre Rodrigo COELHO

Universidade Tecnológica Federal do Paraná (UTFPR)

Departamento Tecnologia de Alimentos Londrina/PR-Brasil e-mail: arcoelho@utfpr.edu.br

Ivane Benedetti TONIAL

Universidade Tecnológica Federal do Paraná (UTFPR)

Departamento Tecnologia de Alimentos Francisco Beltrão/PR - Brasil e-mail: ivane@utfpr.edu.br

\ Autor Correspondente / Corresponding Author

Recebido: Abr. 07, 2014 Aprovado: Jan.14, 2015

\section{Resumo}

Os consumidores costumam associar os produtos cárneos processados a uma imagem negativa em função dos teores de gordura saturada, sódio e aditivos químicos que apresentam. $O$ trabalho teve por objetivo estudar a influência da adição de farinha de semente de linhaça dourada (Linum usitatissimum L.) como substituto de gordura suína e da utilização de sal com teor reduzido de sódio nas características físicas, químicas, microbiológicas e sensoriais de hambúrgueres de carne bovina. Visando tornar o hambúrguer mais saudável, seis formulações foram desenvolvidas mudando as concentrações de sal lighte de farinha de linhaça. Os resultados demonstraram que a adição de 10,0\% de farinha de semente de linhaça dourada em substituição a $100,0 \%$ do toucinho contribuiu para o aumento ( $\mathrm{p}<$ $0,05)$ do teor de proteínas. A adição de $5,0 \%$ de farinha de linhaça dourada em substituição a $50,0 \%$ do toucinho refletiu em boas notas para todos os atributos sensoriais avaliados. Houve aumento $(p<0,05)$ dos percentuais de ômega-3 e cinzas, e redução $(p<0,05)$ dos lipídios totais e valor calórico, independente dos níveis de adição da farinha. A substituição de toucinho por farinha de semente de linhaça contribuiu para o menor encolhimento e melhor rendimento, bem como para maior retenção de umidade e de gordura dos hambúrgueres. O sal light não interferiu negativamente nas características microbiológicas dos hambúrgueres e quando associado com a adição de 5,0\% de farinha de linhaça contribuiu para melhor $(p<0,05)$ sabor e aroma. Os resultados sugeriram que a adição de 5,0\% de farinha de semente de linhaça dourada como substituto de $50,0 \%$ da gordura suína, bem como a redução de $60,1 \%$ do sódio em hambúrgueres de carne bovina, se caracterizou alternativa viável do ponto de vista nutricional e sensorial, contribuindo ainda para o maior rendimento do produto após o cozimento.

Palavras-chave: Produto cárneo; Qualidade lipídica; Ômega-3; Cloreto de potássio.

\section{Summary}

Consumers tend to have a negative image of processed meat products, due to their contents of saturated fat, sodium and chemical additives. This work aimed to study the influence of adding golden flaxseed flour (Linum usitatissimum L.) as a substitute for pork fat as well as using reduced sodium salt, on the physical, chemical, microbiological and sensory profiles of beef burgers. With a view to making the burgers healthier, six formulations were developed with different concentrations of light salt and flaxseed flour. The results showed that the total replacement of pork fat by $10.0 \%$ of golden flaxseed flour significantly increased $(p<0.05)$ the protein content. The burgers with the addition of $5.0 \%$ golden flaxseed flour to replace $50.0 \%$ of the pork fat presented good scores for all the sensory attributes evaluated. Independent of the percentage of flour added to the burgers, the omega-3 and ash contents increased $(p<0.05)$, while the total lipids, caloric value and fat content of the dry matter showed a significant decrease $(p<0.05)$. The replacement of pork fat by flaxseed flour contributed to reduced shrinkage and a higher yield, as well as burgers showing greater moisture and fat retention. The use of light salt did not affect the antimicrobial potential and when combined with $5.0 \%$ of flaxseed flour significantly improved the flavour and taste $(p<0.05)$. The results suggested that the addition of $5.0 \%$ golden flaxseed flour as a substitute for $50.0 \%$ saturated fat and a sodium reduction of $60.1 \%$ in the burgers was a viable alternative for the nutritional and sensorial attributes, as well as providing a higher yield after cooking.

Key words: Meat product; Lipid quality; Omega-3; Potassium chloride. 


\section{Introdução}

A alimentação é evidenciada como uma das mais importantes atividades humanas, podendo refletir significativamente na qualidade de vida e saúde das pessoas.

Segundo Karanja et al. (2007), nas últimas décadas têm ocorrido algumas mudanças nos hábitos alimentares da população, desencadeadas pela escassez de tempo para preparar alimentos no domicílio. Oliveira et al. (2013) complementaram que essas mudanças são também decorrentes da maior oferta de alimentos industrializados e de rápido preparo como, por exemplo, hambúrguer, salsicha, salame, mortadela, linguiça, empanado e almôndegas.

Em decorrência da sua praticidade de preparo e por possuir nutrientes que alimentam e saciam a fome rapidamente, o hambúrguer se tornou um produto consumido por todas as classes populares (NOVELLO e POLLONIO, 2012). No entanto, devido aos consideráveis conteúdos de gordura saturada e sódio (advindo em sua grande maioria do cloreto de sódio adicionado durante a formulação), o consumo demasiado desse tipo de produto pode ser prejudicial à saúde humana (OLIVEIRA et al., 2013), podendo ocasionar aumento da pressão arterial, excesso de gordura no sangue e obesidade, doenças estas tidas como problemas de saúde pública no mundo todo e que, em tempos recentes, têm acometido, além de adultos e idosos, crianças (TONIAL et al., 2010; NILSON et al., 2012; BUSCH et al., 2013). A preocupação com relação aos teores de gordura saturada e sódio é aumentada ao se observar as tabelas nutricionais de hambúrgueres de marcas reconhecidas nacionalmente. Em média, para cada $100 \mathrm{~g}$ do produto 6,6 g é gordura saturada e 1,02 g é sódio, correspondendo a $24 \%$ e $34 \%$, respectivamente, do valor diário recomendado pela Organização Mundial da Saúde para esses ingredientes (COMPER DELIVERY, 2014).

Nesse sentido, a redução dos conteúdos de sódio e gordura animal pode ser relevante para a melhoria da qualidade nutricional do hambúrguer. Em contrapartida, a literatura (SILVA et al., 2007; COXSON et al., 2013) relata a importância da gordura para o sabor, aroma e textura dos alimentos, bem como do efeito preservativo do sódio contribuindo para a maior conservação dos produtos, além de proporcionar sabor salgado a eles, se caracterizando, portanto, desafios tecnológicos para a indústria cárnea.

Diante do exposto, reduzir o conteúdo de gorduras saturadas através da adição de uma farinha de origem vegetal, e por isso incorporar gorduras insaturadas e substituir parcialmente o sódio por outro tipo de sal, pode se caracterizar alternativa para tornar o hambúrguer um produto cárneo mais saudável.

Dos vegetais, a linhaça é um dos mais ricos em ácidos graxos poli-insaturados, apresentando elevados teores de ácidos graxos da série ômega-3, os quais podem contribuir para a redução do risco de diversas doenças crônicas e degenerativas, motivos que justificaram a sua utilização como ingrediente em derivados cárneos (MOLENA-FERNANDES et al., 2010). Por não ter interferido de forma negativa na aceitação dos produtos, o uso de cloreto de potássio em formulações cárneas também tem sido exaltado (NASCIMENTO et al., 2007; CIRIANO et al., 2013).

Visando o desenvolvimento de um produto cárneo mais saudável, formulou-se um hambúrguer de carne bovina com substituição parcial e total de gordura suína por farinha de semente de linhaça dourada, utilizando sal contendo cloreto de potássio em substituição parcial do cloreto de sódio. Foi verificada a influência dessas substituições nas características físicas, nutricionais e sensoriais do produto desenvolvido.

\section{Material e métodos}

Como fonte de ácidos graxos poli-insaturados utilizou-se a linhaça (Linum usitatissimum L.), uma planta pertencente à família das lináceas e da variedade dourada. A farinha de semente de linhaça dourada foi obtida por trituração da semente seca em processador industrial de alimentos. O sal light (marca Línea) utilizado nas formulações era constituído, segundo o fabricante, de $66,0 \%$ de cloreto de potássio em substituição ao cloreto de sódio, antiumectante fosfato tricálcico e iodato de potássio.

\section{Formulação dos hambúrgueres}

Os hambúrgueres foram preparados segundo indicado por Terra (1998) com algumas modificações. A carne utilizada foi proveniente de paleta bovina que, após a retirada do tecido conjuntivo aparente, foi moída em disco de $8 \mathrm{~mm}$ e o toucinho em disco de $5 \mathrm{~mm}$, ambos, reservados em recipientes distintos. À carne (moída) foram adicionados primeiramente a água e o sal para a extração das proteínas miofibrilares.

Após conveniente mistura, os demais ingredientes (proteína texturizada de soja; pimenta branca moída; alho e cebola em pó; glutamato monossódico e eritorbato de sódio (antioxidante) foram adicionados à massa cárnea um a um nas proporções demonstradas na Tabela 1, com exceção da farinha de semente de linhaça, da gordura e do tipo de sal.

A massa cárnea foi dividida em 6 porções, às quais foram adicionados o toucinho, a farinha de linhaça e o sal (light ou convencional) em diferentes concentrações, originando os tratamentos apresentados na Tabela 2. 
Farinha de linhaça dourada como substituto de gordura animal em hambúrguer de carne bovina com redução de sódio OLIVEIRA, D. F. et al.

\section{Análises físico-químicas}

As amostras de hambúrgueres foram analisadas quanto ao teor de umidade, cinzas e proteínas de acordo com técnicas da AOAC (CUNNIFF, 1997). Os lipídios totais extraídos segundo método proposto por Bligh e Dyer (1959). O teor de carboidratos foi obtido por diferença entre $100,0 \%$ e a soma dos percentuais de umidade, cinzas, proteínas e lipídios totais conforme descrito no manual do Instituto Adolfo Lutz (2008).

O valor calórico foi obtido pela somatória dos teores de carboidratos e proteínas, multiplicados por quatro, e de lipídios, multiplicados por nove, de acordo com os coeficientes de Atwater (TAGLE, 1981).

O teor de extrato seco total foi obtido pela soma dos percentuais de cinzas, proteína, lipídios e carboidratos (KINDSTEDT e MISTRY, 1997).

O conteúdo de sódio do sal light foi determinado em fotômetro de chama da marca Analyser, modelo 910M, calibrado com soluções padrão de cloreto de sódio a 99,5\% (Vetec) nas concentrações de 100 mg/L, 50 mg/L, $20 \mathrm{mg} / \mathrm{L}, 10 \mathrm{mg} / \mathrm{L}$ e $5 \mathrm{mg} / \mathrm{L}$.

Os lipídios totais foram submetidos ao processo de transesterificação para a preparação dos ésteres metílicos de ácidos graxos, conforme método 5509 da ISO (1978). Após separação dos ésteres metílicos de ácidos graxos (EMAG), estes foram analisados em cromatógrafo

Tabela 1. Ingredientes não variáveis nas formulações dos hambúrgueres.

\begin{tabular}{lc}
\multicolumn{1}{c}{ Ingredientes } & Formulação (\%) \\
\hline Carne bovina & 74,97 \\
Água & 8,50 \\
Proteína texturizada de soja & 4,00 \\
Pimenta branca moída & 0,04 \\
Cebola em pó & 0,09 \\
Alho em pó & 0,09 \\
Glutamato monossódico & 0,22 \\
Eritorbato de sódio & 0,09 \\
Total & 88,0 \\
\hline
\end{tabular}

gasoso modelo 431-GC da marca Varian, equipado com coluna capilar de sílica fundida VF-5 ms (30 m de comprimento, 0,25 mm de diâmetro interno e 0,25 $\mu \mathrm{m}$ de Carbowax 20 M) e detector de massa modelo 210-MS da mesma marca. A temperatura inicial da coluna foi de 80 ${ }^{\circ} \mathrm{C}$ seguida de duas rampas de aquecimento: a primeira taxa de aquecimento foi de $10^{\circ} \mathrm{C} \cdot \mathrm{min}^{-1}$ até $100^{\circ} \mathrm{C}$ e a segunda, de $15^{\circ} \mathrm{C} \cdot \mathrm{min}^{-1}$ até $250^{\circ} \mathrm{C}$ permanecendo nessa temperatura por 5 minutos. As temperaturas do injetor e detector foram $200{ }^{\circ} \mathrm{C}$ e $250{ }^{\circ} \mathrm{C}$, respectivamente. $\mathrm{O}$ fluxo do gás de arraste (He) foi de $1 \mathrm{~mL} \cdot \mathrm{min}^{-1}$ e a razão de divisão da amostra (split) foi de 1:50. As injeções foram realizadas em duplicatas e o volume de injeção foi de $5 \mu \mathrm{L}$. A identificação dos ésteres metílicos de ácidos graxos foi realizada por comparação com os espectros de massa da biblioteca do software do equipamento e por comparação do tempo de retenção dos constituintes da amostra com padrões Sigma (EUA). Os dados foram calculados como percentual de área normalizada dos ácidos graxos totais.

\section{Cocção dos hambúrgueres}

Os hambúrgueres foram submetidos ao cozimento no estado congelado em grelha elétrica a uma temperatura de $200{ }^{\circ} \mathrm{C}$. Padronizou-se um tempo médio de 4 minutos para cocção de ambos os lados dos hambúrgueres, tempo este necessário para que atingisse uma temperatura de $75{ }^{\circ} \mathrm{C}$ no centro do produto (ARISSETO e POLLONIO, 2005).

\section{Características físicas após cocção}

O rendimento de cocção, retenção de água, retenção de gordura e encolhimento foram determinados de acordo com metodologias descritas por Seabra et al. (2002), Marques (2007) e Piñero et al. (2008), respectivamente.

\section{Análises microbiológicas}

Os hambúrgueres foram analisados para contagem de coliformes a $45^{\circ} \mathrm{C}$, Staphylococcus coagulase positiva e Clostridium sulfito redutor a $46^{\circ} \mathrm{C}$, bem como ausência de Salmonella spp. (BRASIL, 2003).

Tabela 2. Ingredientes variáveis nas formulações dos hambúrgueres.

\begin{tabular}{ccccc}
$\begin{array}{c}\text { Formulações } \\
\text { (F) }\end{array}$ & $\begin{array}{c}\text { Farinha de linhaça } \\
\mathbf{( \% )}\end{array}$ & $\begin{array}{c}\text { Toucinho } \\
\text { F1 }\end{array}$ & $\begin{array}{c}\text { Tipo de sal } \\
(\%)\end{array}$ & $\begin{array}{c}\text { Total } \\
\text { (\%) }\end{array}$ \\
F2 & 0,00 & 10,0 & $2,0^{*}$ & 12,0 \\
F3 & 0,00 & 10,0 & $2,0^{* *}$ & 12,0 \\
F4 & 5,00 & 5,00 & $2,0^{*}$ & 12,0 \\
F5 & 5,00 & 5,00 & $2,0^{* *}$ & 12,0 \\
F6 & 10,0 & 0,00 & $2,0^{*}$ & 12,0 \\
\hline F: & 10,0 & 0,00 & $2,0^{* *}$ & 12,0 \\
\hline
\end{tabular}

F: Formulação; F1: Controle. *Sal comum (99,0\% de cloreto de sódio); ** Sal light (66,0\% de cloreto de potássio em substituição ao cloreto de sódio). 
Farinha de linhaça dourada como substituto de gordura animal em hambúrguer de carne bovina com redução de sódio OLIVEIRA, D. F. et al.

\section{Análises sensoriais}

As análises sensoriais foram realizadas depois de o projeto ter sido aprovado pelo Comitê de Ética em Pesquisa da Universidade Tecnológica Federal do Paraná, tendo recebido parecer favorável para o seu desenvolvimento e registrado sob nº 325.710.

Os hambúrgueres foram avaliados por teste de aceitação usando uma escala hedônica de 9 pontos, variando de gostei extremamente (9) a desgostei extremamente (1), seguido de teste de intenção de compra, no qual 72 julgadores não treinados foram solicitados a informar a sua preferência para cada amostra avaliada quanto aos atributos sabor, aroma, textura, aparência e impressão global durante o teste de escala hedônica (NOVELLO e POLLONIO, 2012).

\section{Análise estatística}

Os resultados físico-químicos, das características físicas e do teste de aceitação foram submetidos à análise de variância (ANOVA) a 5,0\% de probabilidade e pelo teste de média Tukey, através do software Statística versão 7.0 (STATSOFT, 2004).

Tabela 3. Parâmetros físico-químicos da farinha de semente de linhaça dourada.

\begin{tabular}{lr}
\multicolumn{1}{c}{ Parâmetros } & \multicolumn{1}{c}{ Média } \\
\hline Umidade (\%) & $7,18 \pm 0,21$ \\
Cinzas (\%) & $2,91 \pm 0,03$ \\
Proteínas (\%) & $25,75 \pm 0,27$ \\
Lipídios totais (\%) & $43,69 \pm 0,29$ \\
Carboidratos (\%) & $20,47 \pm 0,15$ \\
Valor calórico (kcal.100 $\mathrm{g}^{-1}$ ) & $578,09 \pm 0,14$ \\
Extrato seco total (\%) & $92,82 \pm 0,09$ \\
\hline
\end{tabular}

Os resultados são médias de triplicatas com as respectivas estimativas do desvio padrão.

\section{Resultados e discussão}

Os resultados das análises físico-químicas obtidos para a farinha de semente de linhaça dourada e para os hambúrgueres são apresentados nas Tabelas 3 e 4 , respectivamente.

Os teores de lipídios (43,69\%) e proteínas (25,75\%) encontrados para a farinha de semente de linhaça apresentaram-se acima dos valores encontrados por Martin et al. (2006), os quais descreveram que a semente desse vegetal contém de $30,0 \%$ a $40,0 \%$ de gordura e entre $20,0 \%$ e $25,0 \%$ de proteína. Diferentemente de Martin et al. (2006), Trucom (2006) encontrou que a linhaça chega a apresentar até $50,0 \%$ de gordura. Entretanto, diferenças na composição centesimal dos vegetais podem estar relacionadas com o clima da região, bem como decorrentes da safra.

Segundo a Tabela 4, independente do nível de adição de farinha de linhaça houve aumento significativo $(p<0,05)$ nos teores de umidade, cinzas e redução dos lipídios totais, valor calórico e extrato seco total.

Ao desenvolverem e analisarem hambúrguer de carne bovina adicionado de farinha de semente de linhaça dourada, Novello e Pollonio (2013) encontraram teores de umidade superior $(68,61 \%)$ e de cinzas $(1,90 \%)$ inferior aos obtidos nesse estudo. Bragagnolo e Rodriguez-Amaya (2002), em estudo sobre o conteúdo lipídico de diferentes cortes de carne suína, encontraram alto percentual de gordura saturada no toucinho $(38,0 \%)$. Os percentuais de lipídios obtidos nesse estudo foram diferentes dos verificados por Novello e Pollonio (2013), que encontraram maiores teores de lipídios em hambúrguer adicionado de farinha, óleo e semente de linhaça.

A redução do teor de lipídios totais observada nessa pesquisa pode ser explicada pela redução proporcional de gordura animal (toucinho) conforme houve a adição

Tabela 4. Parâmetros físico-químicos dos hambúrgueres na forma in natura.

\begin{tabular}{|c|c|c|c|c|c|c|}
\hline \multicolumn{7}{|c|}{ Formulações } \\
\hline Variáveis & F1 & F2 & F3 & F4 & F5 & F6 \\
\hline Umidade (\%) & $60,74 \pm 1,21^{\mathrm{Aa}}$ & $60,99 \pm 0,81^{\mathrm{aA}}$ & $62,95 \pm 0,60^{\mathrm{bA}}$ & $62,83 \pm 0,73^{\mathrm{bA}}$ & $62,73 \pm 0,39 \mathrm{Ba}$ & $62,67 \pm 0,47^{\mathrm{bA}}$ \\
\hline Cinzas (\%) & $2,52 \pm 0,13^{\mathrm{aA}}$ & $2,49 \pm 0,18^{\mathrm{aA}}$ & $2,91 \pm 0,04^{\mathrm{bA}}$ & $2,89 \pm 0,48^{b A}$ & $2,88 \pm 0,14^{\mathrm{CA}}$ & $2,85 \pm 0,26^{c A}$ \\
\hline Proteínas (\%) & $18,94 \pm 0,09 \mathrm{aA}$ & $18,94 \pm 0,94^{\mathrm{aA}}$ & $18,81 \pm 0,93^{a A}$ & $18,95 \pm 0,23^{\mathrm{aA}}$ & $20,36 \pm 0,38^{b A}$ & $20,45 \pm 0,51^{b A}$ \\
\hline Lipídios (\%) & $14,96 \pm 0,11^{\mathrm{aA}}$ & $14,82 \pm 0,91^{\mathrm{aA}}$ & $12,42 \pm 0,49^{\mathrm{bA}}$ & $12,48 \pm 0,14^{\mathrm{bA}}$ & $11,42 \pm 0,43^{\mathrm{bA}}$ & $11,42 \pm 0,57^{\mathrm{bA}}$ \\
\hline CAR (\%) & $2,84 \pm 0,38^{\mathrm{aA}}$ & $2,85 \pm 0,47^{\mathrm{aA}}$ & $2,91 \pm 0,53^{\mathrm{aA}}$ & $2,85 \pm 0,21^{\mathrm{aA}}$ & $2,61 \pm 0,34^{a A}$ & $2,61 \pm 0,62^{\mathrm{aA}}$ \\
\hline EST (\%) & $39,57 \pm 0,11^{\mathrm{aA}}$ & $39,01 \pm 0,34^{\mathrm{aA}}$ & $37,25 \pm 0,45^{A b}$ & $37,17 \pm 0,47^{\mathrm{bA}}$ & $37,27 \pm 0,25^{\mathrm{bA}}$ & $37,33 \pm 0,53^{\mathrm{bA}}$ \\
\hline GES (\%) & $37,81 \pm 0,54^{a A}$ & $37,99 \pm 0,48^{\mathrm{aA}}$ & $33,34 \pm 0,12^{\mathrm{bA}}$ & $33,57 \pm 0,04^{\mathrm{bA}}$ & $30,64 \pm 014^{\mathrm{bA}}$ & $30,59 \pm 0,12^{b A}$ \\
\hline VC (kcal.100 g $\left.{ }^{-1}\right)$ & $223 \pm 0,14^{\mathrm{aA}}$ & $220 \pm 0,86^{a A}$ & $199,46 \pm 0,97 \mathrm{bA}$ & $199,52 \pm 0,47^{\mathrm{bA}}$ & $194,66 \pm 0,48^{\mathrm{bA}}$ & $195,02 \pm 0,54^{\mathrm{bA}}$ \\
\hline $\mathrm{Na}\left(\mathrm{mg} .100 \mathrm{~g}^{-1}\right)$ & $867 \pm 0,55^{a}$ & $363 \pm 0,23^{b}$ & $867 \pm 0,55^{a}$ & $346 \pm 0,11^{b}$ & $933 \pm 0,62^{a}$ & $383 \pm 0,15^{b}$ \\
\hline
\end{tabular}

Os resultados são médias de triplicatas com as respectivas estimativas do desvio padrão; Valores na mesma linha seguidos de letras iguais minúsculas não diferem entre si $(p>0,05)$ com relação ao parâmetro físico-químico; Valores na mesma linha seguidos de letras iguais maiúsculas não diferem entre si $(p>0,05)$ com relação ao tipo de sal utilizado (análise de variância - ANOVA e teste de Tukey); CAR: carboidratos; VC: valor calórico; EST: extrato seco total; F1: formulação controle (0,0\% linhaça, 10,0\% toucinho, sal comum); F2: 0,0\% linhaça, 10,0\% toucinho, sal light; F3: 5,0\% linhaça, 5,0\% toucinho, sal comum; F4: 5,0\% linhaça, 5,0\% toucinho, sal light; F5: 10,0\% linhaça, 0,0\% toucinho, sal comum; F6: (10,0\% linhaça, 0,0\% toucinho, sal light. 
farinha de linhaça, o que também explica os menores valores calóricos encontrados nessas formulações, visto que os lipídios são nutrientes calóricos ( $\left.9 \mathrm{kcal} . \mathrm{g}^{-1}\right)$.

Foi verificado que F2 apresentou redução $(p<0,05)$ de 58,1\% de sódio em relação a F1; F4 de 60,1\% ( $<<0,05)$ em comparação a F3, tendo sido observado que F6 apresentou conteúdo de sódio 58,9\% menor ( $p<0,05)$ que F5. Os maiores teores de sódio encontrados nos hambúrgueres em relação aos encontrados no sal light podem ser decorrentes dos demais ingredientes utilizados na elaboração do produto, principalmente, da carne, toucinho, antioxidante (eritorbato de sódio) e do realçador de sabor (glutamato monossódico). Nascimento et al. (2007) observaram que a substituição de $25,0 \%$ de $\mathrm{NaCl}$ não interferiu na capacidade de retenção de água, sabor salgado e estabilidade da emulsão de salsichas. Aliño et al. (2010) constataram que a substituição de até $45,0 \%$ do conteúdo de sódio por uma mistura de sais contendo $25,0 \%$ de $\mathrm{KCl}, 15,0 \%$ de $\mathrm{CaCl}$ e 5,0\% de $\mathrm{MgCl}$ manteve as características físicoquímicas e microbiológicas de lombo suíno desidratado.

Nas Tabelas 5 e 6 são apresentados os resultados da composição de ácidos graxos da farinha de semente de linhaça e dos hambúrgueres, respectivamente.

Tabela 5. Percentual de ácidos graxos na farinha de semente de linhaça.

\begin{tabular}{cc} 
Ácidos graxos & Farinha de semente de linhaça \\
$16: 0$ & $0,54 \pm 0,01$ \\
$18: 0$ & $3,11 \pm 0,09$ \\
$18: 1 n-9$ & $21,98 \pm 0,03$ \\
$18: 1 n-7$ & $2,55 \pm 0,08$ \\
$18: 2 n-6$ & $17,63 \pm 0,18$ \\
$18: 3 n-6$ & $0,50 \pm 0,05$ \\
$18: 3 n-3$ & $52,09 \pm 0,43$ \\
$22: 1 n-9$ & $0,25 \pm 0,05$ \\
OUTROS & $1,36 \pm 0,05$ \\
Somatórios & Farinha de semente de linhaça \\
AGPI & $70,22 \pm 0,20$ \\
AGMI & $24,77 \pm 0,12$ \\
AGS & $3,65 \pm 0,08$ \\
OUTROS & $1,36 \pm 0,05$ \\
$n-6$ & $18,13 \pm 0,23$ \\
n-3 & $52,09 \pm 0,43$ \\
Razões & Farinha de semente de linhaça \\
AGPI/AGS & $19,24 \pm 0,48$ \\
n-6/n-3 & $0,35 \pm 0,01$ \\
\hline
\end{tabular}

Os cálculos dos teores dos ácidos graxos foram feitos por integração das áreas dos picos e os resultados expressos em porcentagem de área (\%); Resultados são médias de 2 repetições com as respectivas estimativas dos desvios padrões; AGPI: ácidos graxos poli-insaturados; AGMI: ácidos graxos monoinsaturados; AGS: ácidos graxos saturados; n-6: ácidos graxos ômega-6; n-3: ácidos graxos ômega-3; AGPI/AGS: razão entre ácidos graxos poli-insaturados/ saturados; n-6/n-3: razão entre ácidos graxos ômega-6/ômega-3.
De acordo com Calderelli et al. (2008), a linhaça apresenta altos níveis de AGPI, especialmente de $\alpha$-linolênico (LNA - 18:3n-3). Essa afirmação reforça os resultados obtidos nesse estudo para o somatório de AGPI $(70,22 \%)$ e conteúdo de n-3 (52,09\%) na farinha de semente de linhaça, o que contribuiu para o aumento $(\mathrm{p}<0,05)$ de AGPI e LNA para os hambúrgueres adicionados de 5,0\% (F3 e F4) e 10,0\% (F5 e F6) da farinha em substituição parcial e total da gordura suína (toucinho), respectivamente.

Dos AGMI encontrados para a farinha de semente de linhaça, o ácido oleico (18:1n-9) apresentou-se em maiores concentrações. No caso particular dos AGPI, o ácido $\alpha$-linolênico (LNA - 18:3n-3), seguido do ácido linoleico (LA - 18:2n-6) apresentou-se em maior proporção em relação aos demais, sendo este último o predominante em todas as formulações de hambúrgueres. Para Lehninger et al. (2011), o aumento de LNA (18:3n-3) em alimentos é considerado um fator importante, uma vez que este é o principal ácido ômega-3 (n-3) e precursor de outros ácidos graxos da série n-3 no organismo.

A adição de 5,0\% e 10,0\% de farinha de semente de linhaça dourada em substituição ao toucinho levou a um aumento na ordem de 6,4\% e 11,2\%, respectivamente, de AGPI nas formulações em relação ao controle (F1), sendo verificada redução dos percentuais de AGS na ordem de 17,0\% para o hambúrguer com 5,0\% da farinha de linhaça e de $38,7 \%$ para aqueles adicionados de $10,0 \%$ de farinha. Esses resultados corroboram os de outros estudos sobre a redução de gordura animal em diferentes produtos cárneos por meio da adição das mais variadas fontes vegetais de ácidos graxos insaturados. Em estudo realizado com salsichas pela substituição de toucinho por óleo de girassol, Asuming-Bediako et al. (2014) observaram redução de 12,0\% de AGS e aumento de $25,0 \%$ de AGPI.

Segundo recomendações do Departamento Americano de Saúde (DEPARTMENT OF HEALTH, 1994), para ser considerada saudável em relação às doenças cardíacas a razão entre os somatórios dos ácidos graxos ômega-6 e ômega-3 (n-6/n-3) deve ser no máximo 4,0, e a razão entre os somatórios dos ácidos graxos poli-insaturados e saturados (AGPI/ AGS) deve ser maior que 0,45, ou seja, é sugerido que o consumo de ácidos graxos n-6 não seja superior à quantidade de ácidos graxos n-3, bem como um maior consumo de ácidos graxos poli-insaturados em relação à quantidade de ácidos graxos saturados. Verificou-se que os hambúrgueres contendo farinha de semente de linhaça se apresentaram condizentes com os valores preconizados pelo Departamento Americano de Saúde tanto em relação à n-6/n-3 quanto para AGPI/AGS, enquanto que as formulações sem farinha de linhaça (F1 e F2) apresentaram n-6/n-3 muito acima do que é 
Farinha de linhaça dourada como substituto de gordura animal em hambúrguer de carne bovina com redução de sódio OLIVEIRA, D. F. et al.

recomendado, podendo se caracterizar um risco à saúde do consumidor.

Os resultados das características físicas após a cocção dos hambúrgueres formulados são apresentados na Tabela 7.

Foi observado que quanto maior a quantidade de farinha de linhaça dourada adicionada, maior $(p<0,05)$ foi o rendimento, bem como a retenção de água e de gordura dos hambúrgueres após processo de cocção. A adição de farinha de linhaça contribuiu ainda para o menor $(p<0,05)$ encolhimento dos hambúrgueres desenvolvidos. Esse resultado é decorrente da retenção de maior quantidade de água pelas fibras que compõem a semente de linhaça, o que implica também em maior rendimento.

Costa (2004) também verificou que a utilização de uma mistura de farelo e fibra de aveia proporcionou ao hambúrguer rendimento superior $(15,0 \%)$ ao do controle após o cozimento. Seabra et al. (2002) obtiveram resultados semelhantes aos encontrados nesse estudo, revelando que hambúrgueres de carne ovina com 2,0\% de farinha de aveia apresentaram menor $(p<0,05)$ encolhimento, maior rendimento e capacidade de retenção de água, bem como menor teor de gordura após cocção. Bourscheid (2009) também constatou menor ( $p$ $<0,05)$ percentual de encolhimento e maior $(p<0,05)$

Tabela 6. Composição dos principais ácidos graxos (\%) dos hambúrgueres na forma in natura.

\begin{tabular}{|c|c|c|c|c|c|c|}
\hline \multirow{2}{*}{ Ácidos graxos } & \multicolumn{6}{|c|}{ Formulações } \\
\hline & F1 & F2 & F3 & F4 & F5 & F6 \\
\hline $16: 0$ & $1,38 \pm 0,04^{a}$ & $1,35 \pm 0,03^{a}$ & $1,48 \pm 0,02^{\mathrm{ab}}$ & $1,51 \pm 0,06^{b}$ & $1,50 \pm 0,07^{b}$ & $1,43 \pm 0,15^{\mathrm{ab}}$ \\
\hline $17: 1 n-7$ & $2,69 \pm 0,07^{a b}$ & $2,56 \pm 0,01^{a b}$ & $2,57 \pm 0,07^{\mathrm{ab}}$ & $2,56 \pm 0,09^{a b}$ & $2,55 \pm 0,11^{b}$ & $2,33 \pm 0,018^{a}$ \\
\hline $18: 0$ & $27,63 \pm 0,99^{a}$ & $28,12 \pm 0,13^{a}$ & $22,79 \pm 0,16^{b}$ & $23,09 \pm 0,63^{b}$ & $22,94 \pm 0,83^{c}$ & $20,89 \pm 0,17^{c b}$ \\
\hline $18: 2 n-6$ & $54,41 \pm 1,59^{a}$ & $54,36 \pm 0,76^{a}$ & $46,98 \pm 0,41^{b}$ & $46,91 \pm 0,65^{b}$ & $37,33 \pm 0,43^{c}$ & $37,20 \pm 0,01^{c}$ \\
\hline $18: 3 n-6$ & $7,27 \pm 0,53^{a}$ & $7,13 \pm 0,61^{a}$ & $4,80 \pm 0,54^{b}$ & $4,81 \pm 0,19^{b}$ & $4,62 \pm 0,22^{b}$ & $4,52 \pm 0,37^{b}$ \\
\hline $18: 3 n-3$ & $0,83 \pm 0,08^{a}$ & $0,81 \pm 0,08^{a}$ & $14,07 \pm 0,15^{b}$ & $14,04 \pm 0,10^{b}$ & $22,25 \pm 0,48^{c}$ & $22,11 \pm 0,28^{c}$ \\
\hline $20: 4 n-6$ & $0,19 \pm 0,01^{a}$ & $0,18 \pm 0,03^{a}$ & $0,16 \pm 0,02^{a}$ & $0,15 \pm 0,01^{a}$ & $0,15 \pm 0,02^{a}$ & $0,15 \pm 0,03^{a}$ \\
\hline $20: 5 n-3$ & $0,16 \pm 0,02^{a}$ & $0,16 \pm 0,02^{a}$ & $1,30 \pm 0,02^{b}$ & $1,29 \pm 0,03^{b}$ & $3,94 \pm 0,10^{c}$ & $3,61 \pm 0,02^{d}$ \\
\hline $20: 3 n-6$ & $0,18 \pm 0,03^{a}$ & $0,18 \pm 0,04^{a}$ & $0,16 \pm 0,01^{a}$ & $0,17 \pm 0,01^{a}$ & $0,16 \pm 0,01^{a}$ & $0,14 \pm 0,01^{a}$ \\
\hline $20: 0$ & $0,90 \pm 0,02^{a}$ & $1,09 \pm 0,15^{a}$ & $0,97 \pm 0,06^{a}$ & $0,91 \pm 0,02^{a}$ & $1,07 \pm 0,01^{a}$ & $1,04 \pm 0,07^{a}$ \\
\hline $22: 6 n-3$ & $0,97 \pm 0,04^{a}$ & $0,98 \pm 0,07^{a}$ & $0,92 \pm 0,09^{a}$ & $0,92 \pm 0,07^{a}$ & $3,62 \pm 0,30^{b}$ & $3,26 \pm 0,25^{b}$ \\
\hline OUTROS & $3,40 \pm 0,02^{\mathrm{ab}}$ & $3,08 \pm 0,065^{c}$ & $3,79 \pm 0,13^{a b}$ & $3,80 \pm 0,17^{d}$ & $3,39 \pm 0,24^{a b}$ & $3,32 \pm 0,29^{a b}$ \\
\hline Somatórios & F1 & F2 & F3 & F4 & F5 & F6 \\
\hline AGPI & $64,01 \pm 0,90^{a}$ & $63,81 \pm 0,01^{a}$ & $68,39 \pm 0,19^{b}$ & $68,29 \pm 0,86^{b}$ & $72,06 \pm 1,07^{c}$ & $71,00 \pm 0,95^{b c}$ \\
\hline AGMI & $2,69 \pm 0,14^{\mathrm{ab}}$ & $2,56 \pm 0,06^{\mathrm{ab}}$ & $2,57 \pm 0,08^{a b}$ & $2,55 \pm 0,11^{a b}$ & $3,01 \pm 0,35^{b}$ & $2,33 \pm 0,01^{a}$ \\
\hline AGS & $29,90 \pm 0,98^{a}$ & $30,55 \pm 0,06^{a}$ & $25,25 \pm 0,24^{b}$ & $25,36 \pm 0,93^{b}$ & $21,55 \pm 0,48^{c}$ & $23,35 \pm 0,07^{b c}$ \\
\hline OUTROS & $3,40 \pm 0,98^{a b}$ & $3,08 \pm 0,15^{a}$ & $3,79 \pm 0,13^{a b}$ & $3,80 \pm 0,17^{b}$ & $3,39 \pm 0,24^{a b}$ & $3,32 \pm 0,29^{a b}$ \\
\hline$n-6$ & $62,06 \pm 0,03^{a}$ & $61,85 \pm 0,15^{\mathrm{a}}$ & $52,10 \pm 0,15^{b}$ & $52,05 \pm 0,84^{b}$ & $42,26 \pm 0,20^{\circ}$ & $42,01 \pm 0,40^{c}$ \\
\hline$n-3$ & $1,79 \pm 0,27^{a}$ & $1,80 \pm 0,12^{a}$ & $14,99 \pm 0,06^{b}$ & $14,96 \pm 0,03^{b}$ & $25,86 \pm 0,77^{c}$ & $25,38 \pm 0,53^{c}$ \\
\hline Razões & F1 & F2 & F3 & F4 & F5 & F6 \\
\hline AGPI/AGS & $2,14 \pm 0,10^{a}$ & $2,09 \pm 0,06^{b}$ & $2,71 \pm 0,03^{c}$ & $2,70 \pm 0,13^{c}$ & $3,35 \pm 0,12^{c d}$ & $3,05 \pm 0,20^{c d}$ \\
\hline$n-6 / n-3$ & $34,69 \pm 2,85^{a}$ & $32,74 \pm 1,42^{a}$ & $3,48 \pm 0,01^{b}$ & $3,48 \pm 0,05^{b}$ & $1,63 \pm 0,04^{b}$ & $1,66 \pm 0,02^{b}$ \\
\hline
\end{tabular}

Os cálculos dos teores dos ácidos graxos foram feitos por integração das áreas dos picos e os resultados, expressos em porcentagem de área (\%); AGPI: ácidos graxos poli-insaturados; AGMI: ácidos graxos monoinsaturados; AGS: ácidos graxos saturados; n-6: ácidos graxos ômega-6; n-3: ácidos graxos ômega-3; AGPI/AGS: razão entre ácidos graxo poli-insaturados/saturados; $n-6 / n-3$ : razão entre ácidos graxos ômega-6/ ômega-3; Os resultados são expressos em percentual de ácidos graxos totais; Letras diferentes na mesma linha indicam diferenças significativas $(p<0,05)$ pelo teste de Tukey.

Tabela 7. Características físicas dos hambúrgueres após cocção por grelhamento.

\begin{tabular}{|c|c|c|c|c|c|c|}
\hline \multicolumn{7}{|c|}{ Formulações } \\
\hline Parâmetros (\%) & $\mathbf{F 1}$ & $\mathbf{F 2}$ & F3 & $\mathbf{F 4}$ & $\mathbf{F 5}$ & F6 \\
\hline Rendimento & $72,75 \pm 0,30^{a A}$ & $72,68 \pm 0,29^{a A}$ & $75,67 \pm 0,27^{\mathrm{bA}}$ & $75,61 \pm 0,47^{\mathrm{bA}}$ & $79,78 \pm 0,26^{\mathrm{cA}}$ & $79,80 \pm 0,49 \mathrm{cA}$ \\
\hline Encolhimento & $36,49 \pm 0,46^{\mathrm{aA}}$ & $36,49 \pm 0,42^{\mathrm{aA}}$ & $17,94 \pm 0,06^{\mathrm{bA}}$ & $17,87 \pm 0,12^{\mathrm{bA}}$ & $11,73 \pm 0,31^{\mathrm{cA}}$ & $11,76 \pm 0,69^{\mathrm{cA}}$ \\
\hline${ }^{*} \mathrm{R} /$ Água & $64,65 \pm 0,46^{\mathrm{aA}}$ & $64,71 \pm 0,27^{\mathrm{aA}}$ & $66,90 \pm 0,31^{\mathrm{aA}}$ & $67,14 \pm 0,31^{\mathrm{aA}}$ & $70,56 \pm 0,60^{\mathrm{bA}}$ & $70,77 \pm 0,25^{\mathrm{bA}}$ \\
\hline${ }^{*} \mathrm{R} /$ Gordura & $3,74 \pm 0,21^{\mathrm{aA}}$ & $3,85 \pm 0,18^{\mathrm{abA}}$ & $4,31 \pm 0,22^{\mathrm{bA}}$ & $4,28 \pm 0,21^{\mathrm{bA}}$ & $4,97 \pm 0,18^{\mathrm{cA}}$ & $4,98 \pm 0,14^{\mathrm{cA}}$ \\
\hline
\end{tabular}

Valores na mesma linha seguidos de letras minúsculas iguais não diferem entre si $(p>0,05)$ pelo teste de Tukey ao nível de $5 \%$ de significância, sendo que as formulações F1 e F2, F3 e F4, F5 e F6, com valores seguidos de letras maiúsculas iguais, não diferem entre si $(p>0,05)$ pelo teste de Tukey ao nível de 5\% de significância com relação ao tipo de sal utilizado; *R: retenção. 
Farinha de linhaça dourada como substituto de gordura animal em hambúrguer de carne bovina com redução de sódio OLIVEIRA, D. F. et al.

percentual de rendimento após cocção, fatores estes economicamente esperados.

Os resultados microbiológicos demonstraram que os hambúrgueres não apresentavam riscos à saúde dos provadores durante a avaliação sensorial, visto que para todas as análises os valores foram condizentes com o limite estabelecido pela legislação pertinente (BRASIL, 2001). Observou-se ainda que a utilização de sal contendo $\mathrm{KCl}$ em substituição parcial de $\mathrm{NaCl}$ não implicou, negativamente, na qualidade microbiológica dos produtos desenvolvidos.

Os resultados do teste de aceitação são demonstrados na Tabela 8.

A adição de 5,0\% e 10,0\% de farinha de linhaça contribuiu para melhor textura, aparência e impressão global $(p<0,05)$ entre as formulações desenvolvidas. Com relação ao sabor, enquanto a formulação adicionada de $5,0 \%$ de farinha de linhaça (F4) e com sal light foi preferida $(p<0,05)$ em relação às demais, com o dobro de farinha de linhaça (10,0\%), independente do tipo de sal utilizado, o sabor e o aroma foram afetados negativamente $(p<0,05)$. Esses resultados insatisfatórios para sabor e aroma são semelhantes aos encontrados por Bilek e Turhan (2009), Pereira e Feihrmann (2009) e Novello e Pollonio (2012) ao avaliarem hambúrgueres de carne bovina também adicionados de 10,0\% de farinha de linhaça. Uma possível explicação para isso pode ser dada pelo que disseram Santos et al. (2008) ao relatarem que altos percentuais de derivados de linhaça dourada em produtos cárneos podem deixar sabor residual acentuado, explicando as baixas notas obtidas nessa pesquisa para o sabor e aroma dos hambúrgueres adicionados de 10,0\% de farinha de linhaça, bem como para os resultados obtidos pelos pesquisadores supracitados.

Assim como a linhaça, o sal light, por conter $\mathrm{KCl}$, pode também deixar residual amargo nos alimentos. Porém, nesse estudo, as piores notas para o sabor (F5 e F6) podem estar associadas à alta concentração de farinha de linhaça $(10,0 \%)$ utilizada nessas formulações

Tabela 8. Aceitação dos hambúrgueres de carne bovina com redução dos teores de sódio e gordura saturada.

\begin{tabular}{lcccccc}
\multicolumn{1}{c}{$\begin{array}{c}\text { Atributos } \\
\text { sensoriais }\end{array}$} & $\mathbf{F 1}^{*}$ & $\mathbf{F 2}^{\text {**}}$ & $\mathbf{F 3}^{*}$ & $\mathbf{F 4}^{* *}$ & $\mathbf{F 5}^{*}$ & $\mathbf{F 6}^{\text {** }}$ \\
\hline Sabor & $6,60 \pm 2,05^{\mathrm{Ba}}$ & $6,86 \pm 2,02^{\mathrm{bA}}$ & $6,87 \pm 2,45^{\mathrm{bA}}$ & $7,80 \pm 1,81^{\mathrm{cB}}$ & $5,60 \pm 1,67^{\mathrm{aA}}$ & $5,39 \pm 1,67^{\mathrm{aA}}$ \\
Aroma & $7,05 \pm 2,11^{\mathrm{bA}}$ & $6,93 \pm 2,03^{\mathrm{bA}}$ & $6,87 \pm 2,52^{\mathrm{bA}}$ & $7,58 \pm 2,11^{\mathrm{cB}}$ & $5,87 \pm 2,26^{\mathrm{aA}}$ & $5,69 \pm 2,48^{\mathrm{aA}}$ \\
Textura & $6,15 \pm 0,56^{\mathrm{aA}}$ & $6,71 \pm 0,36^{\mathrm{bB}}$ & $8,03 \pm 0,47^{\mathrm{cA}}$ & $8,05 \pm 0,22^{\mathrm{cA}}$ & $8,14 \pm 0,23^{\mathrm{cA}}$ & $8,21 \pm 0,17^{\mathrm{cA}}$ \\
Aparência & $5,99 \pm 1,08^{\mathrm{aA}}$ & $5,99 \pm 1,13^{\mathrm{aA}}$ & $7,58 \pm 1,06^{\mathrm{bA}}$ & $7,46 \pm 0,81^{\mathrm{bA}}$ & $7,35 \pm 0,94^{\mathrm{bA}}$ & $7,55 \pm 0,95^{\mathrm{bA}}$ \\
Impressão global & $5,26 \pm 2,34^{\mathrm{aA}}$ & $5,99 \pm 3,87^{\mathrm{bB}}$ & $7,78 \pm 3,24^{\mathrm{cA}}$ & $7,83 \pm 3,88^{\mathrm{cA}}$ & $7,94 \pm 2,19^{\mathrm{cA}}$ & $8,07 \pm 2,71^{\mathrm{cA}}$ \\
\hline
\end{tabular}

Valores na mesma linha seguidos de letras minúsculas iguais não diferem entre si $(p>0,05)$ pelo teste de Tukey ao nível de $5 \%$ de significância, sendo que as formulacões F1 e F2, F3 e F4, F5 e F6, com valores seguidos de letras maiúsculas iguais, não diferem entre si $(p>0,05)$ pelo teste de Tukey ao nível de 5\% de significância com relacão ao tipo de sal utilizado: *Sal comum; **Sal light: F1: controle $(0,0 \%$ linhaça, 10,0\% toucinho, sal comum); F2: 0,0\% linhaça, 10,0\% toucinho, sal light; F3: 5,0\% linhaça, 5,0\% toucinho, sal comum; F4: 5,0\% linhaça, 5,0\% toucinho, sal light; F5: 10,0\% linhaça, 0,0\% toucinho, sal comum; F6: 10,0\% linhaça, 0,0\% toucinho, sal light.

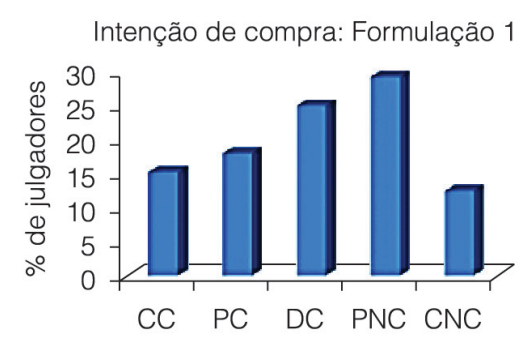

Intenção de compra: Formulação 4

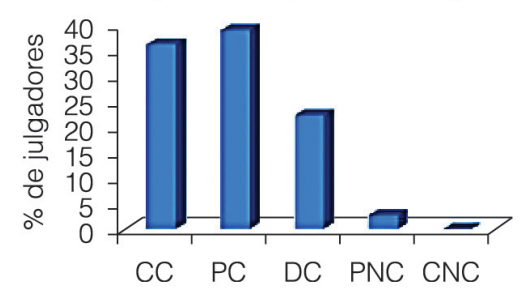

Intenção de compra: Formulação 2

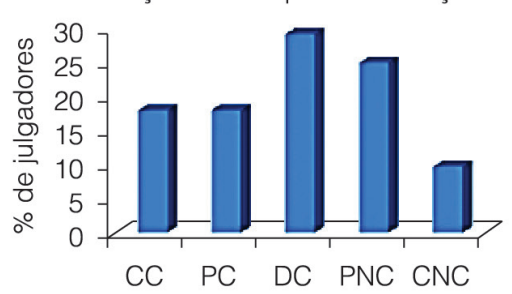

Intenção de compra: Formulação 5

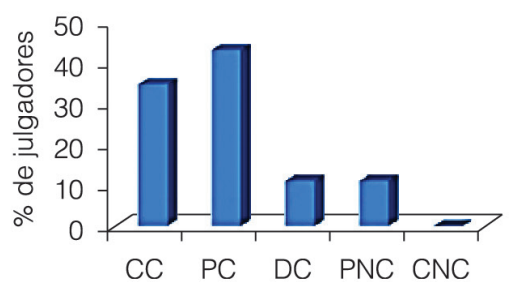

Intenção de compra: Formulação 3

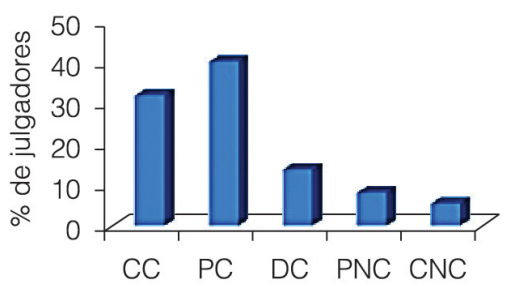

Intenção de compra: Formulação 6

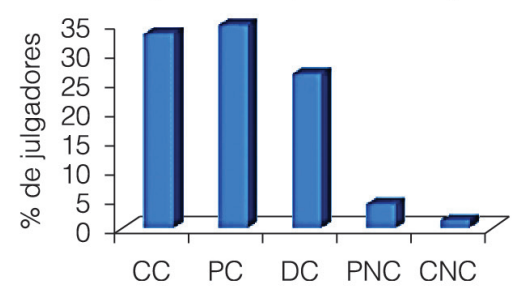

Figura 1. Intenção de compra para os hambúrgueres desenvolvidos. CC: certamente compraria; PC: possivelmente compraria; DC: dúvida se compraria; PND: possivelmente não compraria; CNC: certamente não compraria. 
Farinha de linhaça dourada como substituto de gordura animal em hambúrguer de carne bovina com redução de sódio OLIVEIRA, D. F. et al.

e não ao uso desse tipo de sal. Isso porque aquelas formulações com esse tipo de sal (F2 e F4) apresentaram melhor $(p<0,05)$ sabor em relação às adicionadas de sal comum (F1 e F3).

Os resultados indicaram ainda que $\mathrm{F} 1$ (sal comum) diferiu $(p<0,05)$ de F2 (sal light) com relação à textura e impressão global, assim como para F3 (sal light) e F4 (sal comum) com relação ao sabor e aroma. Em ambos os casos as formulações com sal light apresentaram maiores $(p<0,05)$ médias para os atributos citados, sugerindo que a redução de sódio pode ter interferido positivamente no sabor, aroma, textura e impressão global dessas formulações.

Os resultados do teste de intenção de compra são apresentados na Figura 1.

Os percentuais obtidos no teste de intenção de compra para certamente compraria (CC) e possivelmente compraria (PC) demonstraram um maior interesse de compra por parte dos julgadores para a formulação F4, adicionada de 5,0\% de farinha de linhaça dourada e sal light. Observou-se ainda que, embora as formulações F5 e F6 tenham sido responsáveis pelas piores $(p<0,05)$ notas para o sabor e aroma no teste de aceitação, sem diferença significativa entre si $(p>0,05)$, despertaram nos julgadores boa intenção de compra, seguidas de F4. Esse resultado pode ser explicado pelas altas médias para textura, aparência e impressão global obtidas no teste de aceitação.

\section{Conclusões}

A adição de farinha de linhaça como substituto parcial de gordura saturada proporcionou maior rendimento, menor encolhimento para o hambúrguer após cocção, aumento dos níveis de ácidos graxos poliinsaturados, principalmente de ômega-3, e redução do conteúdo de ácidos graxos saturados.

Os testes sensoriais indicaram uma maior aceitação pela formulação contendo sal com teor reduzido de sódio e adicionada de 5,0\% de farinha de semente de linhaça em substituição a 50,0\% do toucinho.

Nesse sentido, conclui-se que o hambúrguer adicionado de farinha de linhaça e com redução de sódio apresentou características nutricionais e sensoriais satisfatórias, assim como bom potencial de mercado.

\section{Referências}

ALIÑO, M.; GRAU, R.; TOLDRÁ, F.; BLESA, E.; JESÚS PAGÁN, M.; BARAT, J. M. Physicochemical Properties and Microbiology of Dry-cured Loins Obtained Bypartial Sodium Replacement with Potassium, Calcium and Magnesium. Meat Science, Barking, v. 85, n. 3, p. 580-588, 2010. PMID: 20416833. http://dx.doi. org/10.1016/j.meatsci.2010.03.009.
ARISSETO, A. P.; POLLONIO, M. A. R. Avaliação da Estabilidade Oxidativa do Hambúrguer Tipo Calabresa, Formulado com Reduzidos Teores de Nitrito e Diferentes Percentagens de Gordura, Durante Armazenamento Congelado. Higiene Alimentar, v. 19, n. 136, p. 72-80, 2005.

ASUMING-BEDIAKO, N.; JASPAL, M. H.; HALLETT, K.; BAYNTUNJ.; BAKER, A.; SHEARD, P. R. Effects of Replacing Pork Backfat with Emulsified Vegetable Oil on Fatty Acid Composition and Quality of UK-style Sausages. Meat Science, Barking, v. 96, n. 1, p. 187-194, 2014.

BILEK, A. E.; TURHAN, S. Enhancement of the Nutritional Status of Beef Patties by Adding Flaxseed Flour. Meat Science, Barking, v. 82, n. 4, p. 472-477, 2009.

BLIGH, E. G.; DYER, W. J. A Rapid Method of Total Lipid Extraction and Purification. Canadian Journal of Biochemistry and Physiology, Ottawa, v. 37, n. 8, p. 911-917, 1959. http:// dx.doi.org/10.1139/059-099.

BOURSCHEID, C. Avaliação da Influência da Fécula de Mandioca e Proteína Texturizada de Soja nas Características Físico - Químicas e Sensoriais de Hambúrguer de Carne Bovina. 2009. 52 f. Monografia (Bacharelado em Engenharia de Alimentos)-Universidade do Estado de Santa Catarina, Pinhalzinho, 2009.

BRAGAGNOLO, N.; RODRIGUEZ-AMAYA, D. B. Teores de Colesterol, Lipídios Totais e Ácidos Graxos em Cortes de Carne Suína. Ciência e Tecnologia de Alimentos, Campinas, v. 22, n. 1, p. 1037-1043, 2002. http://dx.doi.org/10.1590/S010120612002000100018.

BRASIL. Ministério da Agricultura, Pecuária e Abastecimento. Instrução Normativa $n^{\circ} 62$ de 26 de agosto de 2003. Oficializa os Métodos Analíticos Oficiais para Análises Microbiológicas para Controle de Produtos de Origem Animal e Água. Diário Oficial da República Federativa do Brasil, Poder Executivo, Brasília, DF, 18 de set. 2003.

BRASIL. Ministério da Saúde. Agência Nacional de Vigilância Sanitária. Resolução RDC n.12, de 02 de janeiro de 2001. Regulamento Técnico Sobre os Padrões Microbiológicos para Alimentos. Diário Oficial [da] República Federativa do Brasil, Poder Executivo, Brasília, DF, 2 jan. 2001. p. 1-54.

BUSCH, J. L. H. C.; YONG, F. Y. S.; GOH, S. M. Sodium Reduction: Optimizing Product Composition and Structure Towards Increasing Saltiness Perception. Trends in Food Science \& Technology, Oxford, v. 29, n. 1, p. 21-34, 2013. http://dx.doi.org/10.1016/j.tifs.2012.08.005

CALDERELLI, V. A. S.; BENASSI, M. T.; MATIOLI, G. Substituição da Gordura Hidrogenada por Óleo de Soja na Elaboração de Pães de Linhaça e Avaliação da Aceitabilidade. Ciência e Tecnologia de Alimentos, Campinas, v. 28, n. 3, p. 68-674, 2008. http://dx.doi.org/10.1590/S0101-20612008000300024 
Farinha de linhaça dourada como substituto de gordura animal em hambúrguer de carne bovina com redução de sódio OLIVEIRA, D. F. et al.

CIRIANO, M. G. I.; BERASATEGI, I.; NAVARRO-BLASCO, I.; ASTIASARAN, I.; ANSORENA, D. Reduction of Sodium and Increment of Calcium and Omega-3 Polyunsaturated Fatty Acids in Dry Fermented Sausages: Effects on the Mineral Content, Lipid Profile and Sensory Quality. Journal of the Science of Food and Agriculture, London, v. 93, n. 4, p. 876-881, 2013. http:// dx.doi.org/10.1002/jsfa.5811.

COMPER DELIVERY. Informações Nutricionais de Hambúrguer Bovino. 2014. Disponível em: <http://www.comperdelivery.com. br>. Acesso em: 07 out. 2014.

COSTA, L. O. Processamento e Diminuição do Reprocesso do Hambúrguer Bovino (HBV). 2004. 127 f. Monografia (Graduação em Engenharia de Alimentos)-Universidade Católica de Goiás, Goiânia, 2004.

COXSON, P. G.; COOK, N. R.; JOFFRES, M.; HONG, Y. L.; ORENSTEIN, D.; SCHMIDT, S. M.; BIBBINS-DOMINGO, K. Mortality Benefits From US Population-wide Reduction in Sodium Consumption Projections From 3 Modeling Approaches. Hypertension, Lancet, v. 61, n. 3, p. 564-570, 2013. http://dx.doi. org/10.1161/HYPERTENSIONAHA.111.201293.

CUNNIFF, P. (Ed.). Official Methods of Analysis of the Association of Official Analytical Chemists. 16th. Gaitherburg: AOAC, 1997, cap. 32, v. 2, p. 1-43.

DEPARTMENT OF HEALTH. Report on Health and Social Subjects, Nutritional Aspects of Cardiovascular Disease. London: HMSO, 1994. n. 46.

INSTITUTO ADOLFO LUTZ - IAL. Normas Analíticas do Instituto Adolfo Lutz: métodos químicos para análise de alimentos. São Paulo, 2008. 486 p.

INTERNATIONAL ORGANIZATION FOR STANDARDIZATION ISO. Method ISO 5509. Geneve, 1978. p. 1-6.

KARANJA, N.; LANCASTER, K. J.; VOLLMER, W. M.; LIN, P. H.; MOST, M. M.; ARD, J. D.; SWAIN, J. F.; SACKS, F. M.; OBARZANEK, E. Acceptability of Sodium-reduced Research Diets, Including the Dietary Approaches to Stop Hypertension Diet, Among Adults with Prehypertension and Stage 1 Hypertension. Journal American Dietetic Associaction, Philadelphia, v. 107, n. 9, p. 1530-1538, 2007. http://dx.doi.org/10.1016/j.jada.2007.06.013

KINDSTEDT, F.; MISTRY, V. V. Cheese and Fermented Milk Foods. Michigan: Edwards Brothers, 1997. 323 p.

LEHNINGER, A. L.; NELSON, D. L.; COX, M. M. Princípios de Bioquímica. 5. ed. São Paulo: Sarvier, 2011. 1202 p.

MARQUES, J. M. Elaboração de um Produto de Carne Bovina “Tipo Hambúrguer” Adicionado de Farinha de Aveia. 2007. 71 f. Dissertação (Mestrado em Tecnologia de Alimentos)Universidade Federal do Paraná, Curitiba, 2007.

MARTIN, A. C.; ALMEIDA, V. V.; RUIZ, R. M.; VISENTAINER, L. E. J.; MATSHUSHITA, M.; SOUZA, E. N.; VISENTAINER, V. J. Ácidos Graxos Poli-insaturados Ômega-3 e Ômega-6: Importância e
Ocorrência em Alimentos. Revista de Nutrição, Campinas, v. 19, n. 6, p. 661-670, 2006.

MOLENA-FERNANDES, C. A.; SCHIMIDT, G.; NETO-OLIVEIRA, E. R.; BERSANI-AMADO, C. A; CUMAN, R. K. N. Avaliação dos Efeitos da Suplementação com Farinha de Linhaça (Linum usitatissimum L.) Marrom e Dourada sobre o Perfil Lipídico e a Evolução Ponderal em Ratos Wistar. Revista Brasileira de Plantas Medicinais, Paulínia, v. 12, n. 2, p. 201-207, 2010.

NASCIMENTO, R.; CAMPAGNOL, P. C. B.; MONTEIRO, E. S.; POLLONIO, M. A. R. Substituição de Cloreto de Sódio por Cloreto de Potássio: Influência sobre as Características Físico-químicas e Sensoriais de Salsichas. Alimentos e Nutrição, Araraquara, v. 18, n. 3, p. 297-302, 2007.

NILSON, E. A. F.; JAIME, P. C.; RESENDE, D. O. Iniciativas desenvolvidas no Brasil para a redução do teor de sódio em alimentos processados. Revista Panamericana de Salud Pública, Washington, v. 32, n. 4, p. 287-292. 2012. http://dx.doi. org/10.1590/S1020-49892012001000007

NOVELLO, D.; POLLONIO, M. A. R. Adição de linhaça dourada (Linum usitatissimum L.) e derivados em hambúrgueres bovinos: aceitação sensorial e análise de sobrevivência. Boletim do Centro de Pesquisa e Processamento de Alimentos, Curitiba, v. 30, n. 2, p. 273-286, 2012.

NOVELLO, D.; POLLONIO, M. A. R. Golden flaxseed and its byproducts in beef patties: physico-chemical evaluation and fatty acid profile. Ciência Rural, Santa Maria, v. 43, n. 9, p. 1707-1714, 2013. http://dx.doi.org/10.1590/S0103-84782013000900027.

OLIVEIRA, D. F.; COELHO, A. R.; BURGARDT, V. C. F.; HASHIMOTO, E. H.; LUNKES, A. M.; MARCHI, J. F.; TONIAL, I. B. Alternativas para um Produto Cárneo Mais Saudável: Uma Revisão. Brazilian Journal of Food Technology, Campinas, v. 16, n. 3, p. 163-174, 2013. http://dx.doi.org/10.1590/S198167232013005000021

PEREIRA, A. M.; FEIHRMANN, A. C. Farinha de linhaça em hambúrguer de carne bovina. Revista Nacional da Carne, São Paulo, v. 389, n. 2, p. 110-114, 2009.

PIÑERO, M. P.; PARRA, K.; HUERTA-LEIDENS, N.; MORENO, L. A.; FERRER, M.; ARAUJO, S.; BARBOZA, Y. Effect of Oat's Soluble Fibre ( $\beta$-glucan) as a Fat Replacer on Physical, Chemical, Microbiological and Sensory Properties on Low-fat Beef Patties. Meat Science, Barking, v. 80, n. 3, p. 678-680, 2008.

SANTOS, C.; CAMBERO, M.I.; CABEZA, M. C.; ORDÓNEZ, J. A. Enrichment of Dry-cured Ham with $\alpha$-linolenic Acid and $\alpha$-tocopherol by the Use of Linseed Oil and $\alpha$-tocopheryl Acetate in Pig Diets. Meat Science, Barking, v. 80, n. 3, p. 668-674, 2008.

SEABRA, L. M. J.; ZAPATA, J. F. F.; NOGUEIRA, C. M.; DANTAS, M. A.; ALMEIDA, R. B. Fécula de Mandioca e Farinha de Aveia como Substitutos de Gordura na Formulação de Hambúrguer de Carne Ovina. Ciência e Tecnologia de Alimentos, Campinas, 
Farinha de linhaça dourada como substituto de gordura animal em hambúrguer de carne bovina com redução de sódio OLIVEIRA, D. F. et al.

v. 22, n. 3, p. 244-248, 2002. http://dx.doi.org/10.1590/S010120612002000300008.

SILVA, M. M. C.; RODRIGUES, M. T.; RODRIGUES, C. A. F.; BRANCO, R. H.; LEÃO, M. I.; MAGALHÃES, A. C. M.; MATOS, R. S. Efeito da Suplementação de Lipídios sobre a Digestibilidade e os Parâmetros da Fermentação Ruminal em Cabras Leiteiras. Revista Brasilira de Zootecnia, Viçosa, v. 36, n. 1, p. 246-256, 2007.

STATSOFT. Statistica Data Analysis System. Version 7.0. Tulsa: Statsoft Inc., 2004.
TAGLE, M. A. Nutrição. São Paulo: Artes Médicas, 1981. 233 p. TERRA, N. N. Apontamentos de Tecnologia de Carnes. São Leopoldo: Unisinos, 1998. 216 p.

TONIAL, I. B.; OLIVEIRA, D. F.; BRAVO, C. E. C.; SOUZA, N. E.; MATSUSHITA, M.; VISENTAINER, J. Caracterização Físicoquímica e Perfil Lipídico do Salmão (Salmo salar L.). Alimentos e Nutrição, Araraquara, v. 21, n. 1, p. 91-96, 2010.

TRUCOM, C. A Importância da Linhaça na Saúde. São Paulo: Alaúde, 2006. 151 p. 